\title{
Technological advancements and 2020
}

\section{Muhammad Khurram Khan ${ }^{1}$}

Published online: 27 December 2019

(c) Springer Science+Business Media, LLC, part of Springer Nature 2020

Happy new year and welcome to 2020 !

The last decade has been very progressive in terms of the promising technological advancements and transformations. We are observing unprecedented developments in all the areas of science and technology due to the heavy investment in education, research and development, innovation, and entrepreneurship all over the world. New technologies are converging and making our life easier and more efficient and yet we are likely to see disruptive innovations that have never been considered before.

This landscape of technological convergence is the cradle of many new products, processes and services, and blurring the existence of old-school technologies due to innovation, which is considered as creative destruction of the 21 st century. The modern era of fourth industrial revolution with emerging and enabling technologies and systems e.g. 5G, AI, machine learning, big data, IoT, blockchain, cloud computing, virtual/augmented reality, and cybersecurity is bringing drastic positive impact on improving the quality of life and experience.

All the aforementioned developments are churing out through academic and industrial research, where the former is concerned with discovering the fundamental principles, improving existing theories and adding them to the body of knowledge for more futuristic research, and the latter is focused on product, service and process innovation to have commercial value and industrial development.

Where there are a lot of benefits of this convergence of technologies, innovations, and research, but it also harbors a multitude of new challenges for the publishers and editors to tune the scope of their journals as well as to locate the appropriate and pertinent reviewers to accomplish the review process for publishing high-quality papers. In Telecommunication Systems (TELS), it has been our utmost priority to

Muhammad Khurram Khan

mkhurram@ksu.edu.sa

http://www.professorkhurram.com

1 King Saud University, Riyadh, Saudi Arabia publish high-quality papers, which could make difference on theory and practice and make impact on academia and industry. The impact of a journal could be assessed by different parameters and one of them is the impact factor released by Clarivate analytics in their annual Journals Citations Report (JCR).

We are pleased to share with you that in the JCR 2019, the impact factor of TELS has been increased to 1.707 from 1.527 in JCR 2018. However, it is important to note that our focus is not only on the impact factor to evaluate the excellence, but we also try our level best to keep the quality of contents being published in a timely manner on the hot and interesting topics for our readers.

Recently, we have seen a great surge in the number of submissions with the diversity and confluence of topics in the sub-disciplines of telecommunications field. As discussed earlier, it also challenges publishers and editors to find appropriate associate editors and reviewers to commit the reviewing job with quality and timeline restrictions. To perform a smooth editorial process, we have inducted several new associate editors in 2019 and we warmly welcome them on board. Some associate editors have retired due to their other commitments and engagements and they deserve a gratitude and appreciation for their services to the journal. We also pay our sincere thanks and acknowledge the efforts of existing editorial board for their relentless and sustained contributions to TELS.

Through this editorial, we would like to compliment the efforts of our journal's editorial assistant, Ms. Kanishkaa Sridhar for her support and hard work in executing the smooth editorial workflow. In addition, Ms. Radika Devakumar, production editor at Springer, has always been very active and cooperative to publish the journal contents in a timely manner. Last but not least, the support of Mr. Matthew Amboy, senior editor at Springer, is highly appreciated for the strategic operations and coordination of the journal. 
Finally, we once again wish all a happy, healthy, and fruitful 2020.

Muhammad Khurram Khan, Ph.D.

Editor-in-Chief
Publisher's Note Springer Nature remains neutral with regard to jurisdictional claims in published maps and institutional affiliations. 